\section{Ciência e história no Relatório da Comissão Exploradora do Planalto Central na Primeira República}

Science and history in the report by the First Republic's Comissão Exploradora do Planalto Central
Moema de Rezende Vergara Pesquisadora Adjunta do Mast/MCT Rua Mário Portela, 161/1002 bloco A 22241-000 Rio de Janeiro - RJ - Brasil
VERGARA, M. de R.: Ciência e história no relatório da Comissão Exploradora do Planalto Central na Primeira República. História, Ciências, Saúde - Manguinhos, Rio de Janeiro, v. 13, n. 4, p. 909-25, out.-dez. 2006.

No início da República ressurgiu a idéia de mudar a capital do país para o Planalto Central. Essa idéia já havia sido defendida, no século anterior, pelo Visconde de Porto Seguro. Assim, em 1892 foi organizada uma comissão chefiada por Luiz Cruls, diretor do Observatório Nacional, para demarcar a superfície a ser ocupada pela nova capital. Em 1896 foi publicado o relatório dessa expedição, que circulou pelos principais espaços da opinião pública do Brasil, na forma de resenhas em jornais e em artigos na Revista do Instituto Histórico e Geográfico Brasileiro - IHGB. No texto do Relatório há uma interpenetração de várias questões que estavam afligindo determinados setores da sociedade brasileira da época, como a salubridade do clima brasileiro para o imigrante europeu, a definição das fronteiras e a integração do território.

PALAVRAS-CHAVE: Luiz Cruls; Comissão Exploradora do Planalto Central; Capital Federal.

VERGARA, M. de R.: Science and history in the report by the First Republic's Comissão Exploradora do Planalto Central. História, Ciências, Saúde - Manguinhos, Rio de Janeiro, v. 13, n. 4, p. 909-25, Oct.-Dec., 2006.

The idea of moving Brazil's capital to the Central Plateau reappeared in the early days of the Republic, having been defended one century earlier by the Viscount of Porto Seguro. Headed by Luiz Cruls, director of Brazil's National Observatory, a commission was formed in 1892 to stake out the area where the new capital would stand. The expedition's 1896 report found space in Brazil's main vehicles of public opinion; it was reviewed in newspapers and also in articles published in Revista do Instituto Histórico e Geográfico Brasileiro, the Brazilian Institute for History and Geography's journal. A number of issues then of concern to certain sectors of Brazilian society converge in the body of the report, including the healthiness of Brazil's climate for European immigrants, the definition of the country's borders, and territorial integration.

KEYWORDS: Luiz Cruls; Commission to Explore the Central Plateau; federal capital. 
1 Sobre a coleção Brasiliana ver Hallewell, L. O livro no Brasil (sua história).
D ara trabalhar a relação entre ciência e cultura na Primeira República, escolhi o Relatório da Comissão Exploradora do Planalto Central, publicado em 1894 e redigido por Luiz Cruls, então diretor do Observatório Nacional. No mesmo ano, Floriano Peixoto voltou a convidar Cruls para chefiar a Comissão de Estudos da Nova Capital, cujos objetivos eram escolher a melhor localização para a futura capital dentro da área previamente demarcada, e definir o traçado de uma estrada de ferro ligando Cuiabá e Catalão, no estado de Goiás. Contudo, isso inviabilizava os estudos da mudança da capital, uma vez que o ponto de partida da estrada de ferro, Catalão, estava distante mais de 250 quilômetros do centro de operações da comissão.

Assim, para efeito do presente artigo, trabalharei apenas com o Relatório da viagem de 1892-1893, que fez parte da coleção Brasiliana, por iniciativa de seu filho o literato Gastão Cruls, e foi reeditado por José Olympio em 1957 na coleção Documentos Brasileiros, o que garantiu sua posterior popularização.

Antes de aquele texto ser publicado em forma de relatório, as notícias da expedição já circulavam nos principais jornais do país, como o Jornal do Commercio, e mais tarde, em artigos de revistas, como a do Instituto Histórico e Geográfico Brasileiro - IHGB. No texto do Relatório há uma interpenetração de questões que estavam afligindo determinados setores da sociedade brasileira da época, como a salubridade do clima brasileiro para o imigrante europeu, a definição das fronteiras e a integração do território. Os relatos de Cruls continham uma série de elementos que empolgavam os leitores urbanos, como as possibilidades de exploração das riquezas naturais e descrições do sertão. Cabe também lembrar que naquele momento nem todas as fronteiras nacionais e internacionais do país estavam demarcadas, e que o público acompanhava a conquista do território passo a passo.

Se na passagem do século $X X$ a geopolítica fica num segundo plano em relação à novidade que a natureza do Planalto Central trazia, aquela não foi esquecida por alguns setores da sociedade, como por exemplo, os militares. Não por acaso a edição do Relatório na coleção Brasiliana, ${ }^{1}$ que garantiu a circulação dessa obra ao longo do século XX, se deveu ao auxílio do general Hastimphilo de Moura, que participara da Comissão. Agora é seu aspecto técnico, ou seja, a astronomia em sua aplicação prática que é valorizada, pois na introdução da edição de 1957 se sublinhou o fato de que todos os trabalhos posteriores só retificaram as aferições de Cruls. Esta vertente se tornou mais popular nos inúmeros trabalhos que tratam da história de Brasília, que tem no Relatório da Comissão Exploradora do Planalto Central seu marco zero.

Isto levou o Relatório da Comissão a ser exaustivamente analisado no que se refere à construção da nova capital, em 1960. Uma 
alternativa a essa produção historiográfica teleológica seria ler o Relatório não como o antecedente histórico de Brasília, mas como um diálogo entre a ciência e as preocupações mais gerais da sociedade na Primeira República, época de instabilidade política.

A trajetória da Comissão Exploradora começou com a Constituição de 1891, que decretou no seu artigo $3^{\circ}$, proposto pelo delegado catarinense Lauro Müller, que a futura Capital Federal deveria ser transferida para o planalto central da República. Para acatar a decisão do Congresso Nacional essa comissão foi organizada pelo Ministério da Indústria, Viação e Obras Públicas, que destinou para a missão o montante de 350:000\$000. O texto constitucional já determinava uma área de $14.400 \mathrm{Km}^{2}$ para a nova capital, ou seja, dez vezes o tamanho da Capital Federal no Rio de Janeiro.

Em 1892, cumprindo a resolução do Congresso Nacional, estabeleceu-se a comissão para demarcar e explorar essa região, chefiada por Luiz Cruls, que além de ser diretor do Observatório Nacional era professor da Escola Superior de Guerra. Ele cercou-se de dois astrônomos, Oliveira Lacaille e Henrique Morize, ambos do Observatório, além do médico higienista Antônio Pimentel, do geólogo Eugênio Hussak e do botânico Ernesto Ule. Gastão Cruls chamou a atenção para o fato de que seu pai designou como ajudantes cinco de seus ex-alunos da Escola Superior de Guerra: Tasso Fragoso, Hastimphilo de Moura, Celestino Bastos, Alípio Gama e Antônio Cavalcanti de Albuquerque (Cruls, 1957, p. 22). Cabe lembrar que a presença dos militares no governo dos primeiros anos da Primeira República foi motivo de inúmeras críticas dos que viam a proclamação como uma quartelada ou uma parada militar. Algo bastante incômodo, principalmente para os positivistas que identificavam o militarismo com a fase metafísica, segundo o esquema evolucionista de Augusto Comte. Alguns republicanos, como Quintino Bocaiúva, justificavam a participação dos militares como um meio de implementação de seu desígnio histórico da República, dando às Forças Armadas um papel quase missionário (Carvalho, 1990, passim). Assim, a Comissão Exploradora ofereceu uma oportunidade de mostrar o papel dessa corporação como um instrumento para a realização de um projeto nacional mais amplo, no qual a atuação dos militares devia-se às suas qualidades técnicas e não bélicas, ressalvando-se que no material listado para a expedição constavam armas, cujo uso não foi registrado pelo Relatório.

A expedição, que durou de junho de 1892 a março de 1893, foi equipada com teodolitos, aneróides, bússolas e podômetros, instrumentos meteorológicos e material fotográfico. Todo o equipamento, inclusive barracas, armas e mantimentos, ocupou 206 caixas que viajaram em 9 de junho do Rio de Janeiro para Uberaba, ponto terminal da linha férrea da Companhia Mojiana. Dessa cidade mineira se organizou durante 20 dias a entrada no sertão, que 
tinha como meta Pirenópolis, em Goiás; lá chegando, deu-se o início da expedição em $1^{\circ}$ de agosto.

Para delimitar a zona da futura capital, Cruls optou por adotar o método de determinação das fronteiras dos estados empregado pelos Estados Unidos da América, produzindo assim um quadrilátero, localizado em torno dos 15 aos $16^{\circ}$ de latitude Sul e por volta de $47^{\circ}$ a $49^{\circ}$ de longitude Oeste, em detrimento do método irregular tomando como referência os sistemas orográficos e hidrográfico o que seria mais demorado e custoso. Segundo Cruls, o quadrilátero esferoidal teria ainda a vantagem de produzir uma figura geográfica regular, evitando as questões litigiosas. A geometria da forma, produzida pela astronomia, daria os parâmetros científicos para essa empreitada. A afirmação de Cruls nos levaria a crer que o traçado da linha apaziguaria as disputas de fronteiras que tinham como marcos as montanhas e os rios.

Esse método, que leva em consideração as latitudes de dois arcos de paralelo bem como a longitude de dois arcos meridianos, também permitiria um maior controle da exploração, pois seria possível verificar a todo tempo a posição exata no terreno através da aferição dos instrumentos de astronomia.

Assim, Cruls dividiu a Comissão em quatro equipes que deveriam caminhar em direção aos vértices desse quadrilátero já determinado e depois retornar ao ponto inicial. Todos os itinerários percorridos pela Comissão foram levantados pelo processo americano de caminhamento, servindo-se do podômetro, da bússola e do aneróide, que permitiu não só a verificação das coordenadas, mas a exploração do terreno. Esse trabalho de exploração possibilitou a correção de vários aspectos do conhecimento geográfico, como por exemplo, a retificação da altitude do pico dos Pireneus, "a respeito da qual reinava grande discórdia entre os geógrafos" (Cruls, 1957, p. 71) que se pensava ser cerca de 3 mil metros, opinião partilhada por Emmanuel Liais, Charles Hartt e Orville Derby, mas que segundo os cálculos de Cruls seria de $1.385 \mathrm{~m}$.

O texto estava dividido em duas partes: a primeira, composta pelos relatórios dos chefes das turmas, como o de Cruls (o mais extenso, pois incluiu uma introdução histórica e as instruções gerais), e também os de Henrique Morize, de Tasso Fragoso e de Antônio Cavalcanti. Uma segunda parte era dedicada à análise de especialistas, como a do médico-higienista, do geólogo e do botânico da Comissão. O Relatório fez uso de recursos iconográficos, tais como mapas e as fotografias realizadas por Henrique Morize. Esse Relatório não se dirigia apenas ao Estado, que o encomendou e para quem se apelava para pedir tanto investimentos de infra-estrutura - estradas de ferro, por exemplo - como recursos para se aprofundar os trabalhos de investigação científica; mas para uma opinião pública urbana que desejava informações sobre esse "território desconhecido", ou, 
nas palavras de Euclides da Cunha, desta "terra ignota". O Relatório também se destinava aos especialistas, por revisar e revelar determinados aspectos da natureza daquela região pouco explorada, como também à comunidade internacional, demonstrando que o clima do planalto era próprio para o imigrante (o Relatório teve publicação bilíngüe, em português e em francês).

A moldura que enquadrou todos esses elementos foi a história. Uma determinada historiografia de meados do século XIX fora lembrada para legitimar o projeto, mostrando que o esforço da República em mudar a capital era a realização de um destino já traçado antes mesmo de o Brasil existir enquanto nação. O local para a futura capital que Lauro Müller propôs na Constituinte já havia sido indicado por Varnhagen, conferindo ao historiador, o Visconde de Porto Seguro, o argumento de autoridade de tal projeto. A importância dada à história pode ser vista como uma decorrência do fato de Lauro Müller ser um republicano discípulo de Benjamin Constant que absorvia do positivismo uma visão integrada da história, uma interpretação do passado e do presente e uma projeção do futuro. Segundo José Murilo de Carvalho, essa vertente possuía uma visão de história que tinha suas leis, seus movimentos predeterminando em fases bem definidas, mas a ação humana, especialmente a dos grandes homens, poderia apressar a marcha evolutiva da humanidade (Cf. Carvalho, 1990, p. 42). No caso brasileiro, a grande parte de geração que testemunhou a proclamação da República via nesta uma evolução 'natural' da Monarquia, o que explicaria a quase ausência de resistência monárquica ao novo regime.

Interessante notar que o Relatório da Comissão Exploradora do Planalto Central tenha utilizado o Visconde de Porto Seguro como legitimador de um projeto executado por uma das principais instituições científicas da época. Isto reverte a direção da influência que geralmente se estabelece entre as ciências naturais e o pensamento social brasileiro, na qual é a ciência que oferece os elementos para as possíveis interpretações do Brasil. Essa relação tem por base uma concepção de ciência como discurso de 'verdade', transformando-a em uma fonte inequívoca para as demais reflexões sociais.

Mesmo que a referência ao Visconde não tenha sido originariamente uma escolha pessoal de Cruls, o diretor do Observatório fez uma leitura atenta da obra do historiador, que vai além do determinado pelos constituintes de 1891. Cabe lembrar que em 1900, Cruls publicou no Jornal do Commercio um artigo em que comentava o livro História Geral do Brasil, de Varnhagen. Logo na Introdução do Relatório, Cruls fez extensa referência ao livro de Porto Seguro, afirmando erroneamente que este surgiu em 1834, quando de fato seus vários volumes foram escritos posteriormente, entre os anos de 1854 a 1857 (Rodrigues, 1978, p. 132). Esse lapso poderia ser um 
2 A mesma passagem foi citada por Cruls em seu Relatório, ver p. 62.

3 "Do êxito completo da ultima viagem, tanto em favor da última idéia, - de procurar localidades de sertão mais apropriadas a centros de colonização européia, como de reconhecer, e haver encontrado, mui superior a toda a expectativa, a paragem em que, por uma espécie de pressentimento (bem que apoiado em dados geográficos), havíamos

recomendado para a futura capital da União Brasílica", (Varnhagen, 1877, p. 13). simples erro de impressão, mas também poderia ser uma pista indicando o desejo de reforçar no público a idéia de que o projeto era antigo e não concebido no calor da hora da revolução republicana. Há, até mesmo, um esforço do Relatório em mostrar que a idéia era anterior à Independência, citando vários relatos, como um artigo publicado em 1808 no Correio Brasiliense de Hipólito da Costa. O Relatório também lembra de José Bonifácio que, durante o processo de Independência, havia pensado na mudança da capital. Provavelmente todos esses dados históricos citados por Cruls foram retirados de Varnhagen, que desde 1839 era o grande defensor dessa idéia, exposta numa carta ao IHGB e no Memorial Orgânico de 1849.

Esse apelo à tradição presente no texto do Relatório pode ser considerado como um recurso retórico, que contribuiria para a sua recepção positiva, ao estabelecer simultaneamente uma relação de continuidade e de ruptura com o passado. Para poder entender melhor como se fez essa relação dinâmica com a tradição, cabe interrogar o que significava para Varnhagen a mudança de capital e como esse significado se articulava com o Relatório da Comissão.

No último quartel do século XIX, Varnhagen acirrou a propaganda em torno dessa idéia. Em 1877, chegou a fazer uma viagem ao sertão em direção a Goiás, levando consigo apenas três barômetros. Em seu retorno a Viena, onde era embaixador, o historiador escreveu A questão da capital: marítima ou no interior?, onde afirmou que tinha encontrado o lugar determinado pela própria Providência para a nova capital, que era formado pelas três lagoas Formosa, Feia e Mestre-de-Armas, das quais manam águas para o Amazonas, para o S. Francisco e para o Prata (Varnhagen, 1877, p. 24). ${ }^{2}$ Os principais motivos para a mudança da capital defendida pelo historiador seriam basicamente a segurança - uma capital marítima ficaria à mercê das esquadras inimigas -, a salubridade, pois para ele o "flagelo da febre amarela era um alerta da Providência para a mudança da capital" (Varnhagen, F. A. de. 1877, p. 11), e a falta de integração da corte com as demais províncias. Para ele essa região seria apropriada à colonização européia, da qual era um infatigável defensor. ${ }^{3}$ Também publicou na imprensa da época artigos sobre sua viagem, como n'O Vulgarizador: jornal dos conhecimentos úteis, sob o título "Aos que se proponham viajar no sertão", de 1877.

Mas qual seria o sentido de se defender a mudança da capital para um historiador 'oficial' do Império? A própria noção de Império estava centrada na vastidão de seu território, e um dos fatores que legitimavam a monarquia era o fato de ela ter assegurado a unidade territorial em contraste com o processo disruptivo que fragmentou a América Hispânica em uma coleção de repúblicas oligárquicas (Magnoli, 2002-2003, p. 40). Assim, "como está no corpo o coração" (Varnhagen, 1877, p. 7), deslocar a capital para o 
centro do país produziria uma maior integração ao domínio territorial pelo Estado. Além do que, para Varnhagen, uma capital marítima significava a manutenção do status colonial, no qual o que importava mais era a posição próxima à metrópole, a despeito do contato com as demais províncias.

Cabe notar que essas mesmas razões já haviam sido enumeradas, na Antiguidade, por Cícero, em seu livro Da República, onde ele elogia Rômulo por fundar Roma longe da costa por não ser esta um lugar "apropriado para fundar cidades que pretendem alcançar estabilidade e poderio, porque as cidades marítimas estão expostas, não só a freqüentes perigos, mas a desditas e acontecimentos imprevistos". Mas como aproveitar as vantagens do mar e evitar os seus inconvenientes? Cícero respondeu que o melhor seria construir sua cidade nas margens de um rio cujas águas profundas se esparramam no mar por uma larga desembocadura, procurando assim uma comunicação fácil com o povo todo. Concluiu Cícero sobre a localização de Roma: "Na minha opinião, parecia então adivinhar que essa cidade viria a ser o centro, o coração de um poderoso império; porque, colocada em outro ponto qualquer da Itália, não poderia manter tão vasto domínio" (Cícero, 1973, p. 164).

A repetição da metáfora da capital como 'coração', a identificação do litoral como fonte de perigo e a localização da nova cidade perto de rios navegáveis revelam que Cícero poderia ter sido um modelo para o historiador brasileiro. E apesar de sua filiação aos métodos científicos de Ranke, Varnhagen ainda possuía uma concepção clássica de história, ou seja, uma relação com o passado formada a partir de uma expectativa pedagógica, resumida na expressão latina do próprio Cícero: História magistra vitae. O caráter exemplar da história presente no Memorial Orgânico estava na lembrança da 'humilhação Christie' e na ocupação do Rio de Janeiro pelas tropas francesas no século XVIII. Eram exemplos do passado que deveriam ser aprendidos para que não mais acontecessem. Mas para ele o passado devia ser aprendido não só por seu caráter exemplar, mas também por oferecer elementos para a construção de uma nação nos moldes das demais nações modernas. Em História Geral do Brasil, Varnhagen procurava narrar, a partir da crítica documental, a formação da nacionalidade que seria constituída tanto pelo território legado pela colonização portuguesa quanto, seguindo as diretrizes de Martius, pelo encontro das três etnias, tendo o elemento português um papel civilizador.

A menção e adesão às teses de Varnhagen fizeram a história balizar o trabalho da Comissão, que reiterou as indicações feitas décadas antes pelo Visconde, com mais equipamentos e dados científicos. Essa relação de proximidade com a figura de Varnhagen pode ser vista no texto do Relatório, quando Cruls desejou visitar a 
${ }^{4}$ Cabe notar que essa Comissão, que contemplou vários campos científicos, não se preocupou com a etnografia. Nesse sentido argumentou $\mathrm{O}$ geógrafo alemão Waibel, "não havia nenhum especialista em geografia humana na Comissão Cruls. É portanto compreensível que no relatório Cruls se tenha decididamente dado ênfase aos fatores físicos. Os fatores humanos mereceram ali muito pouca ou nenhuma consideração". (apud Vesentini, 2001, p. 66). lagoa Formosa simplesmente por esta ter sido descrita pelo Visconde (Cruls, 1957, p. 96). Em outra passagem, Cruls, que de modo geral não demonstrava interesse pelas gentes do lugar, ${ }^{4}$ registrou no entanto o contato com um "Sr. Moreira, residente em Formosa, e companheiro do Visconde de Porto Seguro, em sua excursão até a lagoa Formosa..." (Cruls, 1957, p. 93). Esse senhor não chegou a ter seu nome completo registrado no Relatório, mas foi peça importante no reconhecimento da Chapada dos Veadeiros, indicando sua altitude, por meio de um aneróide (barômetro) dado pelo próprio Visconde, de 2 mil metros. Talvez a menção a essa figura se deva mais ao fato de ter conhecido pessoalmente Varnhagen do que a um interesse pelas pessoas do sertão. Assim, o Sr. Moreira pode ser visto como um indício da mediação, mesmo que simbólica, entre o cientista e o Visconde.

Ao analisar a relação das concepções de história de Cruls e Varnhagen, pode-se ver que o primeiro se apropriou de uma visão de história magistra vitae como um exemplo que deve ser aprendido para não mais ser repetido. Mas se para Varnhagen o passado pode ser considerado a base na qual se edificará a nação, tem-se a impressão de que para Cruls o lugar do Brasil será o futuro, e o passado era visto como algo a ser superado. Essa expectativa estava ilustrada na afirmação de que "não devemos nos limitar a considerar as condições atuais da questão [a transferência da capital], mas também as condições futuras" (Cruls, 1957, p. 51). Talvez Cruls quisesse se distanciar das discussões políticas que envolviam tal decisão, para reforçar as esperanças no progresso expressas tanto na construção de estradas de ferro e das obras que tornariam os rios navegáveis, e que auxiliariam na integração do território, quanto nos frutos da imigração européia que contribuiriam para o ingresso do Brasil numa era de civilização. Desta forma, ele acreditava que o país tinha a natureza a seu favor, mas precisa desenvolver suas instituições científicas para melhor aproveitá-la. Parecia haver em Cruls um anseio de reescrever as páginas da história brasileira, agora com maior participação da mão-de-obra européia provinda da imigração. Apesar de a região demarcada possuir uma história própria desde o século XVIII, esta seria apagada e ficara apenas a natureza: "Em resumo, a zona demarcada goza, em sua maior extensão, de um clima extremamente salubre, em que o emigrante europeu não precisa da aclimatação, pois encontrará aí condições climatéricas análogas às que oferecem as regiões mais salubres da zona temperada européia" (Cruls, 1957, p. 108).

Num primeiro momento, tem-se a sensação de que para Cruls a história desempenhou apenas uma função de ornamento, contudo, foi ela quem conferiu legitimidade ao projeto da mudança da capital. No diálogo estabelecido entre o historiador do Império e o cientista já no período republicano havia vários pontos de contato, apesar de a mudança da capital possuir sentidos diferentes para cada um 
deles. Se para o primeiro, a substituição de uma capital marítima por uma no interior serviria de emblema para a consolidação do Império sobre o seu território, fruto da ação conjunta da colonização portuguesa na América e da Providência, para os homens da Primeira República o debate acerca dessa mudança comportava tanto os problemas da fase anterior, como também trazia uma novidade, ou seja, a questão do federalismo.

Uma interpretação possível para a iniciativa do governo federal em formar a Comissão Exploradora seria a concretização de uma idéia difusa de federalismo. O fato de Cruls chefiar essa missão não era necessariamente indício de que ele abraçasse tal ideário político. Enquanto diretor do Observatório Nacional, ele estava obedecendo às determinações do presidente da República, além de considerar a questão do mapeamento do território nacional um problema da ciência. Tanto no Império, quando iniciou sua carreira profis-sional no Observatório por intermédio de D. Pedro II, como na República, Cruls estava semprelutando para aprimorar "os créditos científicos do Brasil" (Cruls, 1898, p. 237).

Em anotações autobiográficas Cruls revelou suas simpatias pelo Imperador e pela nobreza brasileira, afirmando que tivera a felicidade de conhecer o barão de Taunay e seu irmão Hippolite, o visconde de Beaurepaire Rohan e o visconde de Taunay: "Nobreza de casta, mas sobretudo nobreza de sentimentos e de caráter, esta geração altiva deveria servir de exemplo digno a seguir, quando se menciona a pureza e a austeridade dos costumes, o desinteresse e o respeito à palavra empenhada como virtudes cívicas" (Cruls, citado em Barboza, 2004, p. 29). Cruls manteve correspondência com o Imperador exilado, na qual expressou sua aversão aos valores individualistas e arrivistas que emergiram após 1889:

Tivera eu a felicidade de poder embarcar e me afastar destes lugares onde o espetáculo que nos é dado a assistir é tão repugnante! Neste momento, a sorte e os favores sorriem aos mais audaciosos, mas sobretudo aos mais vis. Os outros, estes que recusam do fundo de seu coração a indignação provocada por este estado de coisas, se recolhem no isolamento, esperando, quem sabe? tempos melhores. (Carta de Cruls ao Imperador, 9.5.1891, citada em Barboza, 1994, p. 18)

Comissionado pela República, ele guardou para si suas convicções pessoais, e defendeu com afinco a idéia da mudança da capital, não como uma via de solução política para os problemas do novo regime, mas por razões geopolíticas. Em sua terra natal, a Bélgica, Cruls havia adquirido uma formação de engenheiro militar, chegando a ocupar o posto de segundo tenente. Assim, para um homem de ciência com formação militar, a vulnerável posição marítima da capital seria um forte argumento, não esquecendo que no momento de finalização dos trabalhos de gabinete do Relatório 
da Comissão Exploradora do Planalto Central, eclodiu na cidade do Rio de Janeiro a Revolta da Armada, na qual setores da Marinha tentaram depor Floriano Peixoto. Cruls cedeu parte do pátio do Observatório para que as forças militares leais ao presidente instalassem canhões contra os navios da Armada, chegando a ser atingido por tiros o prédio do Observatório, no Morro do Castelo (Videira, A. A. P., 2003, p. 44). O que reforçou o argumento da vulnerabilidade da capital situada no litoral. Logicamente, os trabalhos da comissão que eram desenvolvidos pelos cientistas do Observatório tiveram de ser suspensos durante o período da Revolta da Armada.

A primeira equipe governamental republicana, que compôs o governo provisório chefiado pelo Marechal Deodoro, possuía uma notória diversidade, incluindo jacobinos, positivistas e republicanos históricos, e não revelava muita clareza em relação ao que viria a ser o federalismo (Cf. Lessa, 1988, p. 50-1). No manifesto republicano de 1870 já havia sido enunciada uma equação que ligava o federalismo à liberdade e a centralização ao absolutismo e, portanto, à monarquia. Naquele momento, os termos 'republicano' e 'federalista' eram praticamente sinônimos, mesmo que, após a proclamação, a relação entre federalismo e liberdade não tenha se mantido. Segundo José Murilo de Carvalho, a grande força por trás do movimento republicano, sobretudo em São Paulo e no Rio Grande, era o federalismo e não a liberdade (Carvalho, J. M., 1999, p. 179).

O governo provisório divulgou seu primeiro decreto, texto no qual emergem as primeiras intenções, incertezas e paradoxos inaugurais da nova ordem. Agora o país tinha novo nome, Estados Unidos do Brasil, e uma nova forma de governo: "República Federativa". Assim, cada "Estado" decretaria sua Constituição definitiva, elegendo "corpos deliberativos e os seus governos". E, finalmente, os procedimentos práticos: a nação será governada por um "Governo Provisório", e nomeará delegados para governar os Estados, podendo ainda neles intervir para garantia da "ordem pública".

A Constituição de 1891 pode ser interpretada como uma demanda pela descentralização política e pela redistribuição dos poderes, mas sobretudo como demanda pela diminuição do tamanho do governo central. Contudo, havia problemas derivados dessa opção pelo federalismo, implantado pelo centro, que em parte dizem respeito às inconsistências do primeiro governo republicano, que além da vaga acessão às idéias federalistas e da defesa da autonomia estatal, não possuía um projeto a respeito de como esses valores poderiam se materializar em uma ordem política e administrativa.

Renato Lessa esclareceu que os primeiros anos republicanos se caracterizaram mais pelo vazio representado pela supressão dos mecanismos institucionais próprios do Império do que pela invenção de novas formas de organização política, ou seja, o fim da Monarquia não implicou a criação imediata e eficaz de uma nova ordem. 
O Brasil amanheceu no dia 16 de novembro de 1889 sem poder moderador. O sistema político brasileiro abriu-se, assim, para uma experiência, nos dez anos que seguiram à Proclamação, na qual ficou desprovido da 'chave' de sua organização institucional. O veto a esse legado implicou o abandono de soluções tradicionais para questões cruciais e pertinentes ao sistema político. Ao acordar, o país não dispunha de nenhuma resposta institucional a respeito de si mesmo: quem faz parte da comunidade política, como se definem as relações entre cidadãos e o sistema político, entre o poder central e as províncias, como se organizarão os partidos e se constituirão as identidades políticas.

Não por acaso a eleição do primeiro presidente civil, Prudente de Morais, em 1894, determinou o fim da Comissão Exploradora. Os recursos do orçamento previstos para os estudos da transferência da capital foram deslocados para a construção da estrada de ferro Catalão-Cuiabá. Desta forma, pode-se constatar que se no governo do militar Floriano Peixoto a solução para o federalismo era tida como uma questão geopolítica de mudança da capital, na fase civil da Primeira República a realização do federalismo buscou a estratégia da composição de agentes políticos.

Segundo Lessa, o início do regime, representado pelos seus primeiros dez anos, teve um papel fundamental na rotinização republicana, configurada a partir de 1898. Muito provavelmente, o presidente Campos Sales (1898-1902) não estava satisfeito em governar o país no Rio de Janeiro, que foi um pólo de agitação, sobretudo durante o período jacobino que durou até 1897. Essa situação era particularmente danosa para a negociação de empréstimos e pagamento da dívida externa, de vez que destruía a confiança dos banqueiros internacionais. A solução foi dada por Campos Sales por meio do sistema que batizou de 'política dos estados', e sua receita foi resumida na conhecida frase: “É de lá [dos estados] que se governa a República, por cima das multidões que tumultuam, agitadas, nas ruas da capital da União" (apud Carvalho, 2001, p. 62).

A República Oligárquica, rotinizada a partir da 'política dos governadores' durante o governo de Campos Sales, não foi construída tendo como contraponto negativo a Monarquia, mas sua 'conturbada infância'. A 'política dos governadores' seria uma forma de encaminhar o problema do poder dos estados sobre a União, sem a necessidade de se lançar mão de um recurso geopolítico, como o deslocamento físico do centro do poder, fazendo que o próprio governo republicano perdesse o interesse pelos trabalhos da Comissão e suspendesse a verba para sua finalização, uma vez que naquele momento a alternativa política para o impasse do federalismo se tornara mais viável. 
${ }^{5}$ Filho de importante família de fazendeiros da região fluminense. Formou-se em Medicina pela Faculdade do Rio de Janeiro. Foi secretário da Comissão de Saneamento do Rio de Janeiro, diretor do Laboratório Bacteriológico Federal, sócio do IHGB e professor da Faculdade de Odontologia e Farmácia de Ribeirão Preto (SP), onde faleceu em 1928.

${ }^{6}$ Antônio Pimentel escreveu três artigos na Revista do IHGB, todos relativos à sua viagem ao Planalto Central: o primeiro de 1900 "A mudança da capital Federal", que é praticamente uma reprodução de seu Relatório de 1894; outro em 1907, sob o título "O Brasil Central", que,

segundo seu elogio fúnebre publicado na mesma revista obteve maior repercussão. E o último foi "Histórico da mudança da capital Federal para um sítio do interior do Brasil", publicado em 1910.
A experiência do federalismo na Primeira República pode ser caracterizada por uma forma de governo que permitiu a mobilização das oligarquias locais, e algumas delas tiveram êxito em organizar-se dentro dos Estados e montar partidos únicos e sólidos, que viabilizaram a manutenção da ordem e a negociação com o governo federal, o que representaria o fracasso da relação entre federalismo e liberdade enunciado pelos republicanos históricos (Cf. Carvalho, 1999, p. 182).

A conclusão do Relatório não fez menção aos problemas políticos daquele momento. Segundo Cruls, um dos resultados mais importantes da Comissão foi a análise do "clima da região explorada" (Cruls, 1957, p. 106). O destaque dado ao clima pode expressar o projeto de Cruls em criticar uma interpretação corrente, tanto no Brasil como no exterior, que via no clima um fator que impedia o progresso do país. Essa tendência estava filiada a uma tradição cientificista que tinha como chave de entendimento da história humana sua subordinação às influências mesológicas. "Coerente, portanto com certa tradição presente no pensamento iluminista que pretendia fundar o mundo moral em harmonia com a Natureza" (Gillespie apud Edler, 1999, p. 20). Essa tradição originada no século XVIII revestia a natureza dos trópicos de uma índole negativa. Buffon, Raynal, Montesquieu e Pauw consideravam a natureza americana inferior à européia, e os americanos uma raça diversa e degenerada em virtude dos efeitos do clima (Cf. Gerbi, 1996).

O clima e a natureza do Planalto Central se tornaram os principais pontos divulgados em outras publicações, como a Revista do IHGB. Vale notar que quem fez a divulgação do Relatório nessa revista foi o médico da Comissão, Antônio Martins de Azevedo Pimentel, ${ }^{5}$ numa série de artigos publicados em 1900, 1907 e $1910 .{ }^{6}$ Em todos esses textos, o autor afirmava o desejo de tornar conhecida uma parte extensa do interior do Brasil, quase paradisíaca, com um clima salubérrimo; solo de grande fertilidade, de riqueza mineral e vegetal; $\mathrm{e}$ "a pureza de um belo céu azul, sempre sereno e calmo e recamado à noite de estrelas do mais vivo fulgor. É aí que deve, um dia, levantar-se a nova capital da florescente República Brasileira" (Pimentel, 1907, p. 332).

A história também possuía um papel importante para o higienista, para quem as várias patologias por ele encontradas não eram decorrência do clima, como se acreditava então, mas dos hábitos do lugar, herança do período colonial. Pimentel se estende longamente sobre a história da ocupação de Goiás nos séculos XVII e XVIII pelos bandeirantes que, segundo o autor, estavam motivados pela descoberta de ouro e pela captura de indígenas. Essa ocupação foi vista como maléfica, pois a ganância gerou um desregramento moral propiciando a expansão da sífilis (para ele o bócio dos habitantes seria uma variante sifilítica) e a subnutrição da população, produzida, segundo Pimentel, pelo completo abandono 
da agricultura em proveito da mineração. Assim, aqui se entende a preocupação do autor com a geologia, pois, para ele seria esse campo que indicaria os meios científicos de desenvolvimento da agricultura, diferentemente do período anterior. Desta forma a nova marcha para o Oeste deveria seguir os critérios científicos tanto da geologia moderna como da higiene. Cabe lembrar que um dos desafios dessa higiene do final do século XIX era justamente a questão da aclimatação do tipo europeu nos trópicos.

O estudo da climatologia era um problema relevante do saber médico nacional, condicionado pelos padrões de cientificidade vigentes nos centros de excelência internacionais. Assim, os estudos sobre o clima uniam tanto médicos como astrônomos. Em seu artigo de 1907, Pimentel afirmou que a visão acerca da salubridade do Brasil Central estava comprometida pela real insalubridade do Rio de Janeiro, e que o conhecimento do clima daquela região através de uma feição mais científica, mais civilizada, traria grandes benefícios para a indústria e agricultura do país (Pimentel, 1907, p. 332).

No século XIX, a nova expansão colonialista fez nascer uma medicina tropical formulada em países europeus, como Inglaterra e França, que advogava que os indivíduos não aclimatados estariam mais expostos às doenças, principalmente de pele e digestivas. Pimentel era um entre os vários cientistas brasileiros que desejavam reverter esse tipo de concepção de nosso clima. Assim, ele afirmava freqüentemente em seus artigos: “É crença corrente e infelizmente partilhada até por homens de alto merecimento científico, que o interior do Brasil é uma região intolerável por causa do seu calor abrasador" (Pimentel, 1957). Quanto à patologia, o médico afirmava: "nenhuma afecção constante da estatística por mim organizada, e que se acha no meu Relatório de 1893, é peculiar à parte explorada do estado de Goiás, nem tão pouco depende do clima" (Pimentel, 1957).

O Relatório expressava o desejo daquele conjunto de cientistas em rever essas concepções, dando um tratamento em bases científicas para o problema. A questão do clima interessava ao campo científico que ao longo do século XIX estava se especializando, como no caso da medicina, que tinha que deparar com a 'patologização dos trópicos'. Muitos médicos alertavam, por exemplo, para o perigo da anemia tropical. Flávio Edler afirma que o debate não era apenas acadêmico. Era uma questão estratégica para a República brasileira, que estava fortalecendo uma política de imigração européia. Por exemplo, argumentava-se que nos indivíduos sujeitos às regiões quentes haveria maior perda de glóbulos vermelhos em decorrência da adaptação ao meio, isto é, o aclimamento poderia predispor o organismo às patologias tropicais (Edler, 1999, p. 74).

O Observatório Nacional já vinha desde a época de Emmanuel Liais, diretor do Observatório Imperial de 1870 a 1884, procurando 
legitimar a convivência da astronomia e da meteorologia, fornecendo parâmetros que seriam seguidos por Luiz Cruls e Henrique Morize (Barboza, 1998, p. 40). Em 1889, este último foi incumbido de escrever, sobre o clima do Brasil, uma curta notícia destinada a ser publicada no volume preparado pelo barão do Rio Branco para a Exposição Universal de Paris, sob o título de Esboço da Climatologia do Brasil. Morize afirmava que naquela data eram muito reduzidos os documentos que podiam servir de base a um trabalho daquele gênero. Esse primeiro trabalho foi ampliado posteriormente na "Contribuição ao Estudo do Clima do Brasil", que consta do Dicionário Histórico, Geográfico e Etnográfico do Brasil, organizado pelo IHGB em 1922. Morize sempre voltou às teses centrais expostas no Esboço:

Quanto ao Brasil inteiro, podemos dizer, concluindo, que ele apresenta ao homem de raça branca européia três regiões diferentes: uma zona, quente e húmida, em que grande parte não pode ser propícia ao seu desenvolvimento; uma segunda zona, mais fresca, onde, com higiene apropriada, ele pode facilmente se adaptar; e uma terceira, onde não há necessidade de aclimação, visto como ali se encontra o mais belo e sadio dos climas (Morize, 1922, p. 90).

Cruls escreveu sobre o clima do Brasil na Revue Scientifique, lançando mão desse trabalho de Morize e de sua experiência no Planalto Central, concluindo o artigo da seguinte forma:

não percamos, contudo, de vista que penetrando-se pelo interior do Brasil, o relevo do terreno acentua-se e que não tarda em elevar-se sobre planaltos, que gozam de climas comparáveis aos das regiões temperadas. Posto que, na verdade, muito incompleto, os dados que acabamos de apresentar permitam, todavia, fazer-se uma idéia quase exata dos caracteres gerais de climatologia brasileira e julgamos ter demostrado a improcedência de opiniões muito facilmente aceitas e que só podemos atribuir à ignorância ou a má fé de alguns autores segundo as quais o clima do Brasil seria pouco salubre, não convindo à colonização européia.

Nós pensamos ao contrário que, em geral, a maior extensão do vasto território do Brasil é absolutamente favorável ao imigrante, porque ele encontra aí clima completamente comparável ao das zonas temperadas da Europa, enquanto que as partes do país menos salubres, e que são pouco numerosas, podem ainda convir-lhe havendo o cuidado de recorrer à higiene apropriada. (Cruls, 1896, p. 234)

Comparando as duas passagens pode-se notar que ambos estavam de acordo com a possibilidade de aclimamento do tipo europeu no território brasileiro. Nas primeiras décadas da República havia claramente uma política imigratória que passava pela questão racial, de 
forma mais explícita, sempre vinculada à colonização - ou seja, o imigrante preferencial é aquele que pretende se fixar como trabalhador rural. O papel do imigrante estava bem definido: concorrer para a formação de um tipo brasileiro, elemento da unidade nacional, pois a nação brasileira do futuro deveria ser uma civilização latina e branca (Seyferth, 1996, p. 48 e 51). Essa geração acreditava que o imigrante iria ajudar a produzir uma "evolução biológica" equivalente à evolução social alcançada pela República. Uma crítica que os republicanos faziam à nacionalidade produzida no Império era de que esta foi feita à força da 'teoria política' de uma monarquia constitucional, mas que mantinha as três raças em estágios evolutivos diferentes (Cunha, 1966, p. 171-2).

Nesse sentido, ao se acreditar que o clima não era favorável para o imigrante europeu, todo esforço que o Estado brasileiro estava fazendo para atrair o europeu se perdia. Assim, esse debate que se abre em torno do tema sobre o clima brasileiro e a adaptação do europeu, no qual participou a comunidade científica brasileira, contribuiu para o fortalecimento de diversas instituições científicas nacionais. Entre elas, o Observatório Nacional se destacou como um dos lugares para onde se dirigia à demanda social sobre uma 'verdade' científica a respeito do tema.

A presente análise do Relatório deseja ver como esse trabalho científico dialogou com as principais preocupações da sociedade brasileira do final do século XIX. A apropriação das idéias de Varnhagen pelos constituintes de 1891, uma vez que o lugar apontado para a futura capital era o mesmo indicado pelo Visconde, pode ser interpretada como uma continuidade com o período anterior, produzindo no público um sentimento de proximidade e familiaridade com o projeto em questão. Mas essa referência tem um efeito de moldura de um quadro que precisa ser preenchido por um conteúdo diverso.

Segundo a crença da época, era a partir do clima e da raça que se escrevia de antemão a história de cada país. Assim, o Planalto Central, com seu clima temperado semelhante à Europa e o fluxo imigratório também europeu, serviria de 'laboratório' para uma nova miscigenação que colocaria o país no rumo 'certo' em direção à civilização.

\section{REFERÊNCIAS BIBLIOGRÁFICAS}

Barboza, C. H. da M. Luiz Cruls, um cientista a serviço do Brasil. 2004

Catálogo da Exposição, Rio de Janeiro: Mast/MCT.

Barboza, C. H. da M. 1998

Sol e a diversidade dos climas na terra. In: Congresso Latino-americano de História das Ciências e da Tecnologia, V. Cadernos de Resumo.

"Processos de Formação de Identidade de Gênero". Rio de Janeiro, Campus da Praia Vermelha/UFRJ. 
Barboza, C. H. da M. 1994

Carvalho, J. M.

Carvalho, J. M. 1999

Carvalho, J. M. 1990

Cícero

Cruls, G.

Cruls, L.

Cruls, L. 1898

Cruls, L. 1896a

Cruls, L. $1896 b$

Cunha, E. da 1966

Edler, F. C. 1999

Gerbi, A. 1996

Hallewell, L. 1985

Lessa, R. 2001

Lessa, R. 1988

Magnoli, D.

Morize, $\mathrm{H}$.

Pimentel, A. M. de A. 1910

Pimentel, A. M. de A. 1907

Rodrigues, J. H. 1978
O encontro do rei de Vênus: a trajetória no Observatório do Castelo no ocaso do Império. Dissertação de Mestrado, Niterói, Universidade Federal Fluminense.

Os três povos da República. In: Carvalho, Maria Alice Resende de (org.) República no Catete. 1. ed. Rio de Janeiro: Museu da República, v. 1, p. 61-87.

Federalismo e centralização no Império Brasileiro: história e argumento. In: Pontos e bordados. Escritos de história e política. Belo Horizonte: Ed. UFMG.

A formação das almas. O imaginário da República no Brasil. São Paulo: Companhia das Letras.

Da República.

São Paulo: Abril (Os Pensadores).

Luiz Cruls - Escorço biobibliográfico.

In: Cruls, Luiz. Planalto Central do Brasil. Rio de Janeiro: J. Olympio.

Planalto Central do Brasil.

Rio de Janeiro: J. Olympio.

Revista Científica.

Revista Brasileira, tomo XV.

Le climat du Brésil.

Revue Scientifique, n. 8, tome VI.

Relatório Parcial da Comissão de Estudos do Planalto Central do Brasil.

Rio de Janeiro: Typo-lith. Carlos Schmidt.

Sem Idade Antiga nem Média. In: Andrade, O. de S. (org.) Euclides da Cunha: antologia. São Paulo: Melhoramentos.

A constituição da medicina tropical no Brasil oitocentista: da climatologia à parasitologia médica. Tese de Doutorado, Rio de Janeiro, Instituto de Medicina Social da Universidade Estadual do Rio de Janeiro. p. 20.

O Novo Mundo: disputa de uma polêmica, 1780-1900.

São Paulo: Companhia das Letras.

O livro no Brasil (sua história).

São Paulo: Edusp.

A invenção da República no Brasil: da aventura à rotina.

In: Carvalho, M. A. R. de (org.) República do Catete.

Rio de Janeiro: Museu da República.

A invenção republicana: Campos Sales, as bases e a decadência da Primeira República brasileira. Rio de Janeiro: Iuperj.

O Estado em busca do seu território.

Terra Brasilis, n. 4-5, p. 27-44.

Contribuição ao estudo do clima do Brasil.

Rio de Janeiro: Imprensa Nacional. p. 90.

Histórico da Mudança da Capital Federal para um sítio do interior do Brasil. Revista IHGB, tomo LXXIII, p. 279-91.

O Brasil Central.

Revista IHGB, tomo LXVIII, p. 260-376.

Teoria da história do Brasil.

São Paulo: Cia. Ed. Nacional. 
CIÊNCIA E HISTÓRIA NO RELATÓRIO DA COMISSÃO EXPLORADORA DO PLANALTO CENTRAL

Seyferth, G.

1996

Construindo a Nação: hierarquias raciais e o papel do racismo na política

de imigração e colonização. In: Maio, M. C.; Santos, R. V. (org.)

Raça, ciência e sociedade. Rio de Janeiro: Ed. Fiocruz/CCBB. p. 41-58.

Varnhagen, F. A. de

1877

A questão da capital: maritima ou no interior?

Vienna d'Austria: Imp. do Filho de Carlos Gerold.

Edição por conta do Autor.

Vesentini, J. W

A capital da geopolítica.

2001

São Paulo: Ática.

Videira, A. A. P.

Henrique Morize e o ideal de ciência pura na República Velha.

2003

Rio de Janeiro: Ed. FGV.

Recebido para publicação em julho de 2005.

Aprovado para publicação em julho de 2006. 